\title{
An Automated Transport Management System
}

\author{
Ms Mithlesh Choudhary
}

\begin{abstract}
Transport demand in most Indian cities has increased significantly due to increase in population as a result of both natural increase and migration from rural areas and smaller towns fast growth of India's population like other developing countries has trigger a greater need for used organized public transport system. Automation of bus transport has been gaining more importance because they provide accurate information of buses like reservation, air charges, route information, bus information etc anywhere and anytime. The dissertation has been divided into six modules based on the functionalities of the system namely, information system module, reservation system module. Administartive management system module, fleet management system module, and warehouse module and financial module. These modules have been designed to build up an integrated system to cover various aspects of automated bus transport management system. They provide full information about the bus enquiry, buses schedules, buses fairs, buses ticket reservation, buses time table enquiry.
\end{abstract}

Objectives of the Proposed Research Work: The main objective behind developing this software is to ease managed bus transportation system. Various modules are used in this dissertation. All function of modules can be developed in this program that is ease to passenger work. Software for managing transportation operations of all types: shippers, airlines, bus, train, taxi, moving companies, transportation rental agencies, etc. These programs feature modules for tracking and managing every aspect of vehicle maintenance, fuel costing, routing and mapping, warehousing, communications, EDI implementations, traveler and cargo handling, carrier selection and management, accounting, etc.

The benefits that automation technology can provide, beyond those achievable with conventional, nonautomated bus operations, include: Permitting precision docking at bus stops, so that physically impaired passengers can more easily gain access to and from the buses and speeding up the loading and unloading processes for all passengers:

- Facilitating maintenance operations and saving labor? ordinarily used to move buses through routine overnight maintenance and cleaning processes;

- Smoother and safer travel for passengers, increasing passenger riding comfort and reducing crash costs for operators; significantly higher vehicle and passenger capacity per lane, by enabling buses to operate at shorter headway than under manual driver control;

- $\quad$ Reduced fuel consumption and emissions for buses that can operate in automated platoons with small enough separations (half vehicle length or less) that aerodynamic drag can be reduced significantly;

- Potentially reduced driver labor costs for the portion of the bus trip that operates on the automated lane.

These six modules have different work in this dissertation:-

\section{Information Management System: Reservation system \\ Administrative Management system Fleet Management System \\ Warehouse Management System Financial Management system}

The need to increase the capacity of public transport and make it more attractive to mitigate the problems of urban congestion and vehicular pollution is broadly recognized. Though rail transit systems provide high capacity and are well suited for high-density corridors, they are expensive and take along time to build. Hence, many countries opt for Buses as a low cost and quicker alternative to increase the capacity of the public transport system. The network of automated reservation, connected to the Data Processing Center of the system, allows for speeding the service of passengers, bringing greater order to accounting and financial reports connected with the commercial activity of large bus stations.

Another property of the system meets the needs of the times - the possibility for selling tickets listing last names and passports. This becomes especially important within the framework of solving the unitary problem of increasing transport security. The system's database contains differentiated technological information including data on: 
- Routes and schedules of routes with up to 10 intermediate stops

- Passenger and baggage fares, discounts and fees, and also about automated rules for their application. Moreover these data can depend on season, day of week and have differing prices on differing routes

- Types of busses with a description of the seat configuration in their cabins, load norms, including the possibility for selling "standing places";

- Norms for sale of seats from the station of departure and from intermediate stations for different routes which take into account reservation of seats for the driver and the reservation of the stationmaster, as well as a reserve of seats for "ongoing" sales;

- Regarding agencies, terminals, and operators (ticketing agents, reservation agents, et al.) working in the system along with their functional authority levels about bus companies and their drivers.

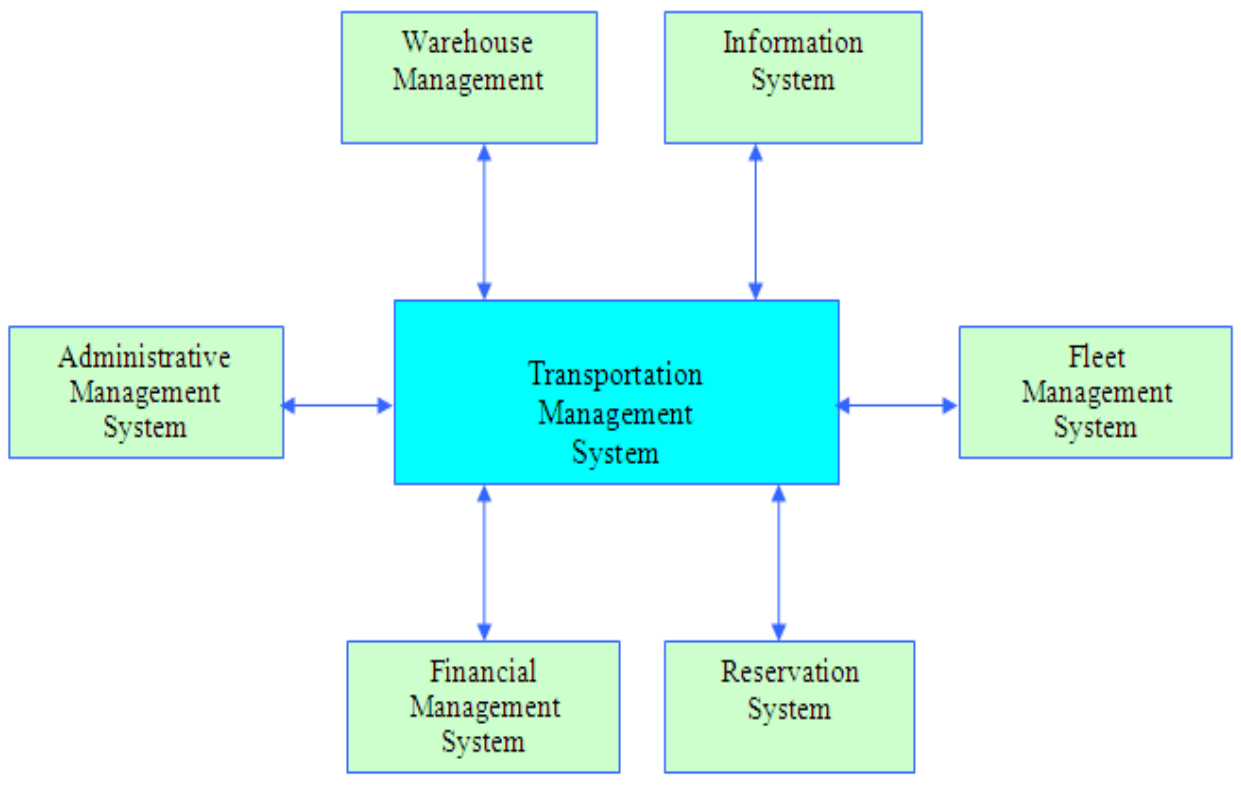

Figure: 1 System Design Architecture

\section{Information Management System:}

The Information Management System module is expected to provide full information about the bus transport system. Information provides to vehicle, route, reservation, cancellation, and fares. According to information module. The bus transport information system intended to be developed seeks to provide people, especially the traveling community access to information, which would allow them choose the optimal route and at the same time effectively manage time. The goal of this project is to develop a pointto-point guide which would provide the following:

- Timing/Frequency of the various buses.

- Buses connecting various places of interest to the commuters.

Shortest possible route for the commuter by taking time or distance into consideration. The total Fare in the chosen path.

\section{Reservation system}

Every State Transport Corporation runs several classes of services to on different routes. Each route has a specific fare for a given class of service and operates of select days and runs through select cities. This system will function as a centralized application for any STC. Authorized booking agents logging into the system will be allowed to make reservations on any route, subject to availability. The system must allow for reservation as well as for back-office administration and reporting.

\section{Administrative Management System}

Administrative Management is the most common type of organizational management. The organization is grouped by areas of specialty within different functional areas (e.g., finance, marketing, and engineering). Some refer to a functional area as a "silo." Communications generally occurs within a single department. If information or project work is needed from another department, a request is transmitted up to the 
department head, who communicates the request to the other department head. Otherwise, communication stays within the department. Team members complete project work in addition to normal department work. There are three functional management system work properly in this project, HR, Planning, Monitoring, manage employee wages, calculate employee salary. Basic functions of management operate through various functions, often classified as planning, organizing, leading/motivating and controlling.

- Planning: deciding what needs to happen in the future (today, next week, next month, next year, over the next 5 years, etc.) and generating plans for action.

- Organizing: making optimum use of the resources required to enable the successful carrying out of plans.

- Leading/Motivating: exhibiting skills in these areas for getting others to play an effective part in achieving plans.

- Controlling: monitoring checking progress against plans, which may need modification based on feedback.

Human resource planning: Many small businesses operate with no employees. One person handles the whole business with perhaps occasional help from family or friends. Making the leap to hiring someone to help is a big one because all of a sudden you need to worry about payroll, benefits, unemployment insurance, and what seems like a myriad of other details. And, this does not even take into consideration the host of problems that can arise from personality conflicts and loss-of-control of all the processes in running your business. , Wage and Salary Administration, Job analysis, Preparation of job descriptions, pay surveys, Compensation, Employment Taxes.

Planning: Planning is a detailed method, formulated beforehand, for managing all or part of a business. It is not something that should be approached haphazardly. While many business owners think of planning simply as a process you need to go through to get funding, there are many other types of planning that may be useful to a small business to help it so, a good business plan will include.

\section{Fleet Management System}

Fleet management of a company's vehicle fleet. Fleet management includes the management of ships and or motor vehicles such as cars, vans and trucks. Fleet (vehicle) Management can include a range of Fleet Management functions, such as vehicle financing, vehicle maintenance, vehicle telemetric (tracking and diagnostics), driver management, fuel management and health \& safety management. Fleet Management is a function which allows companies which rely on transportation in their business to remove or minimize the risks associated with vehicle investment, improving efficiency, productivity and reducing their overall transportation costs, providing 100\% compliance with government legislation (Duty of Care) and many, many more.

\section{Warehouse Management System}

Warehouse Management Systems (WMS) are a key part of the bus depot layout and location, primarily aim to control the movement and storage of buses within a warehouse and process the associated transactions, including staff, employee wages, and total maintenance cost. The systems also direct and optimize bus depot all depot location and facility information.

Bus Depot: A bus garage or bus depot is a type of garage where buses are stored. Many bus garages are on the sites of former car barns or tram sheds, where streetcars or trams were stored, and the operation transferred to buses.

\section{Financial Management System}

The term "financial system" means an information system, comprised of one or more applications, that is used for any of the following:

- Collecting, processing, maintaining, transmitting, and reporting data about financial events;

- Supporting financial planning or budgeting activities.

- Accumulating and reporting cost information.

- Supporting the preparation of financial statements.

A financial system supports the financial functions required to track financial events, provide financial information significant to the financial management of the agency, and/or required for the preparation of financial statements. A financial system encompasses automated and manual processes, procedures, controls, data, hardware, software, and support personnel dedicated to the operation and maintenance of system functions. A financial system may include multiple applications that are integrated through a common database or are electronically interfaced, as necessary, to meet defined data and processing requirements. 


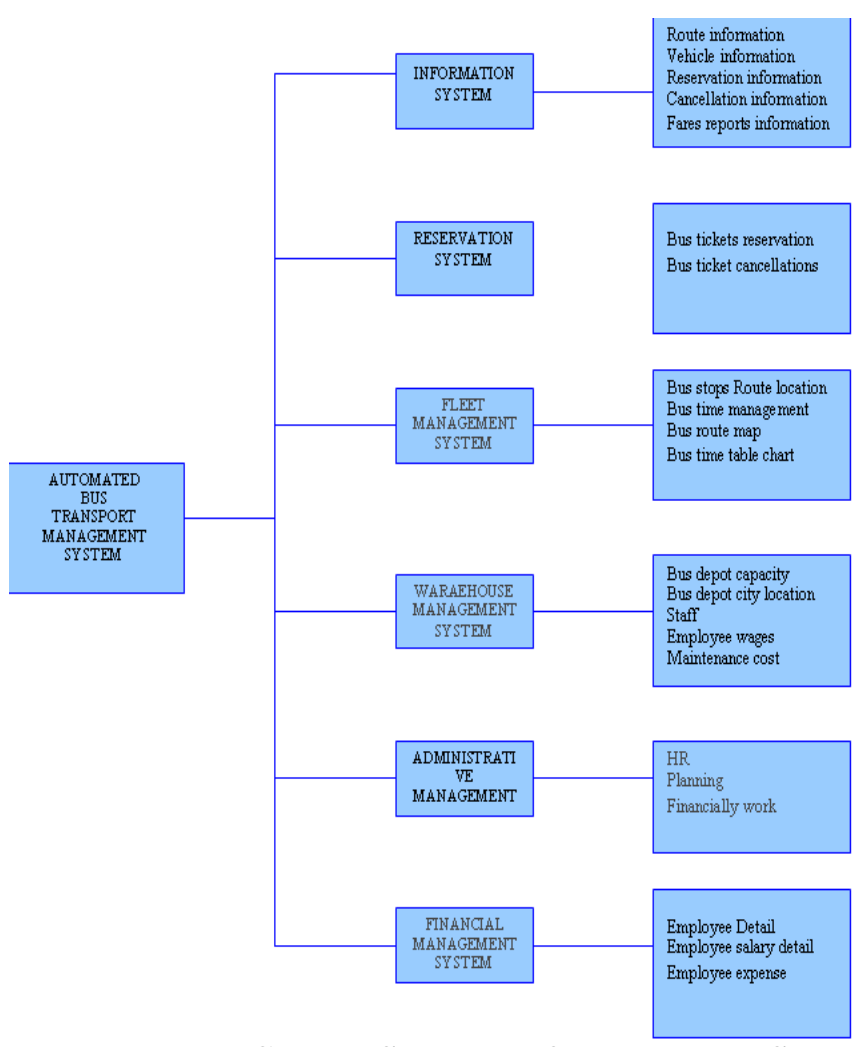

Figure: 2 General Structure of the Proposed System

Module Formulation

The module formulation is divided into six modules these modules are shown below:

1. Information Management System

1.1 Route information

1.2 Vehicle information

1.3 Reservation information

1.4 Cancellation information

1.5 Fares information

2. Reservation System

2.1 Bus Ticket Reservation

2.2 Ticket Cancellation

3. Administrative Management System

$3.1 \mathrm{HR}$

3.2 Planning

3.3 Monitoring-manage time, route, staff, wages and salary

4. Warehouse Management system

4.2 Depot capacity

4.2 Staff/wages

4.3Maintenance cost

5. Financial Management System

5.1 Employee detail

5.2 Salary detail

5.3 Expenses

6. Fleet Management System

6.1 Time management

6.2 Route management 


\section{Concluding Remarks and Future Scope}

We have decided to make efficient software for a transportation company as we have described earlier and in the proper guidance and help of our lectures we are able to achieve our goal in a suitable working Environment.

In last with help of all my teachers and books we made the project according tom our requirement and desires .we make it user friendly it means at starting of our project we have decided to make such a project the enhance our knowledge and analyzing creativity, innovation and we have decided to make the project on transport management system "for is project we decided sql server for data storage it means as a back Endean vb.net for interaction it means as a front- end.

After this we concentrate on the function and modules of a transport company and we try to implementation them in our project like registration a customer for transporting of their material and enquiry for mall information and services that are provide by the company. After this we analyze flow of data in the organization and then we design data flow diagram for modules of our project and according to these diagram and flowcharts we have designed tables in sql server for various forms of the project.

After this we start with most important work, which is designing for forms and when we designed these forms we connect them with database through ADO connectivity the we try interfacing of component of forms with attributes of table of database because of lack of our mind knowledge we are enable to make it online we try to make it online in.

\section{References}

[1]. S.L Bandarkar Dhanpat Rai \& co (Eds.), Vehicle Transport Management.

[2]. G.V Rao Dhanpat Rai \& co, principal of transportation and highway engineering.

[3]. Kumar Gaurav, Swati Agrawal and P.Krishna Reddy, Towards an It-based Bus Information System to Improve Bus Occupancy in Hyderabad, Proceedings of the 7th International Conference on Information Technology, CIT 2004, Hyderabad, India, December 2004. Pp.

[4]. S.Chaudhuri, Umeshwar Dayal, Vagrant (2001), Database Technology for decision support systems, IEEE Computer, pp.48-55, December 2001.

[5]. Delhi Transport Corporation.http://dtc.nic.in 